\title{
Tales of the expected
}

Philip Campbell

\section{Forecasting the future in science is fun but often hopelessly misleading. This publication, commissioned by all the Nature journals, focuses on future developments about which we can be reasonably confident and which will have an impact on the lives of all of us.}

A $s$ the immunologist Peter Medawar once wrote, wise people may develop expectations about the future, but only the foolish make predictions. X-rays, radioactivity and high-temperature superconductors are just three ways in which physicists have taken themselves and other scientists by delighted surprise. Medawar cited the uncovering of genetic polymorphisms within the human leukocyte antigen system as an unanticipatable simultaneous solution to several biomedical conundrums. The unexpected detection by James Lovelock in the 1960s of chlorofluorocarbons in the marine atmosphere stimulated a transformation in the understanding of the stratospheric ozone layer. And so on.

The unpredictability of experimental progress was neatly summarized in 1926 by J. B. S. Haldane: "In the case of both thunderstorms and fever the clue came from measuring the lengths of mercury columns in glass tubes, but what prophet could have predicted this?" Nevertheless, there has always been the uneasy feeling that governments and legislatures, focused ever more on obtaining benefits from science, expect too much of researchers and of research as a whole in the way of premeditated discovery. That is presumably why learned societies find it necessary to highlight in public what is well known to the cognoscenti: the unanticipatable conjunctions of unrelated developments that have led, time and again, to high peaks of scientific and technological progress. The US National Academy of Sciences has gone so far as to generate a series of case studies in its 'Beyond Discovery' education programme (see www4.nas.edu).

Then again, some of the great achievements of science have flowed from predictions. (Or were they expectations only classed as predictions with hindsight?) When an original way of thinking about a problem leads to a mathematical equation with solutions that represent what have hitherto been mysterious phenomena, that may be a triumph. But excitement runs even higher when the same equation yields solutions that match nothing so far seen. Are they mathematical oddities? The negative-energy solutions in Dirac's equation, which gives a quantum mechanical description of an elementary particle, led him to predict particles of equal mass and opposite charge to the elec-

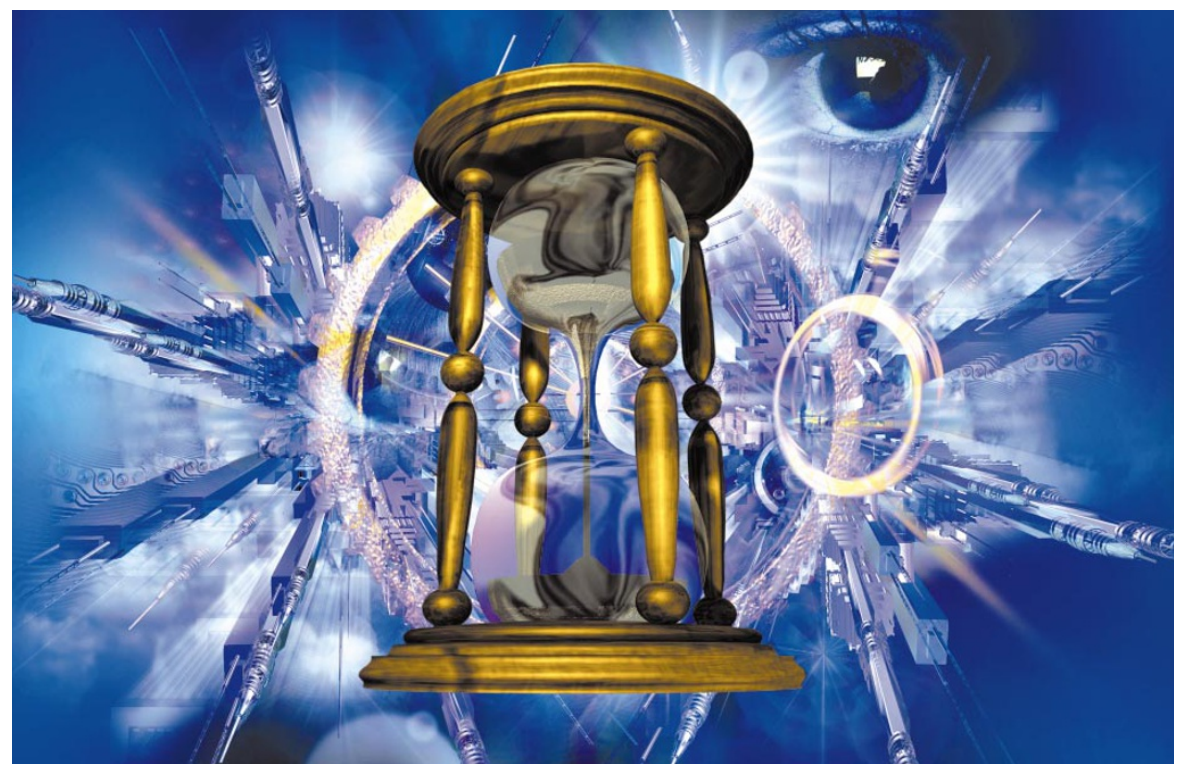

tron. These were subsequently detected when positrons, the first species of anti-matter, were discovered in cosmic rays. Wolfgang Pauli's physical reasoning led him to conclude with confidence that there must be a very weakly interactive particle and (nearly?) massless particle involved in nuclear decaysubsequently identified in the form of the neutrino. Currently the world awaits the detection of the predicted Higgs boson and - less certainly — 'supersymmetric' partners of all known fundamental particles. (Failure to detect a Higgs particle - a keystone of the currently unshakeable standard model of high-energy physics - at CERN's Large Hadron Collider early next decade is highly improbable but, paradoxically, could be an unpredicted boost for particle physics.)

\section{Scarcity of wise prediction}

Such unambiguous predictions, far from foolish, come from within a tightly argued, self-contained theoretical framework based on critical assumptions or hypotheses that may prove false. They stand out among the peaks of science, alongside the unexpected discoveries, and those that were anticipated in principle but still revelatory in actuality, such as the structure of DNA. And not only in physics: witness the analysis that followed Lovelock's work that led atmospheric chemists to predict damage to the ozone layer. It is a shame that, the world being as messy as it is, such clear-cut predictions representing scientists at their best, out on an intellectual limb - are so rare.

The more common and foolish predictions about science are usually much more casual and broad ranging, often based on the blinkered preconceptions of even great scientists - see, for example, Rutherford's notorious dismissal of the possibility of nuclear energy. Looking back at predictions 100 years ago, described by John Heilbron and Bill Bynum on page $\mathrm{C} 86$, is both entertaining and sobering. Nature, hopefully wisely, is straying into predictions only by means of fictions, appearing in our weekly 'Futures' essays. In contrast, this supplement, Impacts of foreseeable science, commissioned with the help of the staff of Nature and of the six Nature monthly journals, is about expectations of what can and might be achieved.

The articles published here are not intended to represent some collective vision, they have not been peer reviewed, nor are they intended to provide balanced surveys. On the contrary: they have been commissioned as representing the scientific hopes and expectations of these particular authors, drawn from among many scientists and professional colleagues who combine a broad overview with an individual outlook. For extra fun, we have interspersed the longer articles with short items about anticipated research relating to a variety of timescales at 
which natural phenomena are known to occur, from $10^{-43}$ to (at least) $10^{17}$ seconds. There is a strong bias in our choice of topics. In the interests of our readership across all disciplines, we have focused on some of the fundamental science that will directly or indirectly touch everybody's lives.

\section{Everyday stuff}

In that context, the physics of everyday matter merits a place because, despite such matter's familiarity, fundamental aspects of its behaviour, especially as described by statistical physics, still provide researchers with some of their most difficult intellectual challenges. Condensed matter physics has already led to new electronic technologies that have transformed our lives, not least in developments in information and materials technologies. These are themselves transforming the ways scientists of all disciplines will accomplish computations, as described by Declan Butler on page C67. Who knows what technologies might materialize following a deeper understanding of common and notso-common transitions between the various phases of matter? Of all the developments discussed in this publication, those are perhaps the most difficult to anticipate in any detail. Philip Ball's article on page C73 thus concentrates on the essential agenda of the subject.

Rather more specific is the expectation that more planets orbiting stars other than the Sun will be discovered. The image of the rising Earth taken by astronauts orbiting the Moon had an impact on many people's views of themselves as members of one population living in perishable but also cherishable conditions. Think, then, of the impact of the image of an Earth-like planet, light-years away, being delivered from a space-based network of interferometers. As Jack Lissauer describes (page C11), such precision is still decades away, but there are likely in the meantime to be other tantalizing planets aplenty.

In highlighting our fragility, the Apollo image was salutary. But we do not understand just how fragile humanity might be, nor what we might do to reduce that fragility. Success at modelling the regional impacts of climate change, for example, still eludes us, let alone societal impacts. We are only now at the stage of developing integrated models incorporating oceans and atmospheres, with necessarily crude representations of uncertain feedbacks involving biota and clouds. Perhaps the most insightful progress will come in a simulatory framework of the sort envisaged by John Schellnhuber on page C19. That will still leave plenty of scope for debate over the application of the precautionary principle as a recipe for societal stagnation or for sensible planetary management.

\section{Biological revolutions}

As is now well understood, biologists are at the threshold of an immense collective leap in knowledge, the impact of which we try to anticipate in some depth. The genes that make up representative genomes across the various kingdoms of life are being identified. The technology is available for mass analyses of gene function and patterns of expression, while the ability to catalogue anybody's genome in a day is now anticipatable, though still lies many years away. Within years we will also have built up libraries of protein structure and function. But the geneticist Eric Lander has characterized molecular and cell biologists as still only approaching a phase of development of their discipline reached by chemists 100 years ago, when the periodic table was first described.

In this supplement we have taken many of those very challenging advances for granted. What will follow? Developmental and evolutionary biologists and palaeontologists will have a wonderful time, as anticipated by Peter Holland on page C41.

But where next for the committed reductionists? Even if one knows all of those elements of an organism, and their individual functions, what could we say about the nature and behaviour of the organism? The answer is: not much, even if the organism consists of a single cell, let alone the $10^{13}$ cells and 200 or so cell types that make up one of Homo sapiens sapiens. This level of analysis takes us to the next step up the ladder whose bottom rung is molecular biology. (The top rung is the science of xenobiology, involving the study of alien life forms. So far we know only one form of life, based on DNA. At this point I will be deliberately foolish and predict the discovery of at least one other form of natural life - not necessarily intelligent - by the end of the next century. But that is a digression.)

Biologists and others have begun to think about systems and networks as such - for example, of neurons and of signalling molecules - but we, or at least Leland Hartwell et al., on page C47, can anticipate such systems analysis of functional, albeit labile, collections of interlinked molecules - or 'modules' - becoming a new norm of biological investigation, crucially aided by the other traditional disciplines and also by computational simulation.

But even ahead of such analysis and understanding, biologists will discover gross characteristics that can be indirectly linked to our molecular constitution. None is likely to be more sensitive, in a societal context, than analysis of cognitive ability and of decision making. Robert Plomin (page C25) and James Nichols and William Newsome (page C35) have their respective views of the power of the sciences to help us understand some of the innate aspects of ability and behaviour. These and other fruits of molecular and organismal biology are readily anticipatable, as are some of the controversies that will ensue. But such applications of fundamental biology can most favourably be seen as part of the wider picture of future improvement in human health. And, as Barry Bloom describes on page C63, such advances are themselves part of a much bigger picture of development and of debate relating to public health, its priorities and economics.

Public ambivalence towards such advances, and more recently towards undoubtedly positive developments in nutrition (see Gordon Conway and Gary Toenniessen, page C55), are nothing new. As the journalist and sociologist of science Jon Turney has described in his book Frankenstein's Footsteps: Science, Genetics, and Popular Culture, the framework for social discussion of contentious science - newspaper coverage, high-profile scientists and hostile representatives of various publics — were all in place at least in the United States and Britain in the 1900s, in time for debates on the chemical basis of life. Aldous Huxley, Julian Huxley and J. B. S. Haldane stimulated such debate in the 1930s as they anticipated much of the developments that have occurred since - and, in Brave New World, rather more. The world's first test-tube baby, Louise Brown, stimulated worldwide agitation, and no-one reading this will need to be reminded of Dolly the sheep - a mammal whose unprecedented origin led to new levels of public debate, at all levels of informedness.

\section{Science's contract}

In the face of such controversies, there is a lot to be said for an enhanced degree of interaction, genuinely two-way, between science and society. Experience suggests that lack of scientific knowledge by the various publics and stakeholders does not hamper fruitful discussion anything like as much as the reluctance of scientists and technologists to become involved in the sometimes heated, often chaotic and occasionally even physically threatening debates.

Michael Gibbons is someone who has long thought about what is increasingly becoming a commonplace idea: a new contract between science and society (see page C81). His agenda is not idealistic, and is wholly practicable, although his definition of socially robust knowledge may raise some eyebrows. Nevertheless, various types of public participation have been undertaken, for example in the United States, Scandinavia, Britain and France. It is surely time to draw together these experiences and for governments to build on them, if they are to have a hope of bridging the gap between the public's imaginations and the ever swifter and, for some, dismayingly unpredictable development of science.

Philip Campbell is the Editor of Nature and Editor in Chief of Nature publications. For a guide to Nature and the monthly journals, and the relationship between them, see http://www.nature.com/author/natureguide.html. 